\title{
LOCAL AND DISTORTIONAL BUCKLING OF AXIALLY LOADED COLD ROLLED SIGMA PROFILES
}

\author{
Katarzyna CIESIELCZYK*, Katarzyna RZESZUT* \\ *Faculty of Civil and Environmental Engineering, Poznan University of Technology, Piotrowo 5, 60-965 Poznan, Poland \\ katarzyna.ciesielczyk@put.poznan.pl,katarzyna.rzeszut@put.poznan.pl
}

received 6 September 2015, revised 19 July 2016, accepted 20 July 2016

\begin{abstract}
In this paper the local and distortional buckling analyses of axially loaded cold-rolled channel and sigma profiles were performed. The critical buckling load was computed by solving the linear eigenvalue problem for different numerical models using Finite Element Method and simplified formulas implemented in Eurocode and proposed by Hancock and Schafer. The buckling analyses were conducted to prove that the sigma cross-section can be successfully replaced by channel cross-section with additional elastic supports placed in folds of the web. It was demonstrated that the folds in the web of the sigma cross-section (additional elastic supports) reduce the slenderness of the web. So, the critical distortional stress can be calculated based on analytical formulas derived for the channel crosssection taking into account the web height between the folds.
\end{abstract}

Key words: Cold Rolled Sigma Profiles, Local And Distortional Buckling, Eurocode 3, Finite Element Method

\section{INTRODUCTION}

Application of thin-walled cold-formed sections increased the importance of local and distortional buckling phenomena which may appear at a similar or lower load level as global instability. In engineering approach buckling modes presented in the Tab. 1 are investigated separately. Global buckling is analysed based on Vlasov theory, which do not takes into account a local instability. Whereas the local buckling is considered based on the concept of effective cross-section. While the distortional buckling is analysed using the simplified analytical formulas derived for equivalent cross-sections including flange with an edge stiffener. An alternative design procedure for cold-formed steel member is the Direct Strength Method widely discussed in (Schafer, 2008). This method employs gross cross-section properties, but requires an accurate calculation of member elastic buckling behaviour. It equals or betters the traditional Effective Width Method implemented in Eurocodes (Eurocode 3). The efficiency of Direct Strength Method is analysed in (Yua and Schafer, 2007) for cold-formed steel C- and Z-section beams through the comparing study of experimental data and results obtained from nonlinear finite element model. It was found that the moment gradient effect on distortional buckling failures can be conservatively accounted for in the Direct Strength Method by using an elastic buckling moment that accounts for the moment gradient. On the other hand in (He et al., 2014) based on experimental data of fixed-ended web-stiffened lipped channel columns eroded by mode interaction behaviour combined with distortional and local deformations authors concludes that the Current Direct Strength Method (DSM) provides very unsafe predictions. Therefore the they proposed two DSM-based design approaches, namely, the nominal strength against local-distortional (NLD) and distortional-local (NDL) procedures. Similar conclusions were drawn in (Wang and Young, 2014) for cold-formed steel channels with stiffened webs subjected to bending. This studies have demonstrated that the local and distortional buckling still a need for of scientific research.

It is worth to mention that distortional buckling of compression members is associated with the deformation of the contour in a form of symmetrical or asymmetrical closing or opening of the section and change of the angle between adjacent walls. Distortional buckling of compression members has been widely discussed in literature. In Lau and Hancock (1990) the authors proposed distortional buckling formulas for columns made of coldrolled channel cross-sections. The distortional buckling analysis was also carried out by (Schafer, 2000). The Schafer's report data was used by Pala (2006) for training and testing a new neural network (NN) to determine of the elastic distortional buckling stress (EDBS) of cold-formed steel C-sections with both end sections pinned. It was found that the proposed NN basedformula can be used for the explicit formulation of various analyses of EDBS, especially when an analytic expression could not be obtained from the results of experimental and numerical studies. The effectiveness of new NN based-formula was tested by parametric study for distortional buckling stress on cold-formed steel presented in Pala and Caglarb (2007). The comparative analysis conducted by Szymczak and Werochowski (2005) showed that the critical distortional stresses calculated according the designing code are overestimated in relation to the formulas proposed by Hancock and Schafer.

An analytical model for predicting the critical stress of distortional buckling of zed and sigma cold-formed steel sections was proposed by Long-yuan and Jian-kang (2008). They derived and validated closed-form formulas providing a good prediction of the distortional buckling stress, despite its simplicity. Next, analyses of distortional buckling of cold-formed sigma purlins using EN1993-1-3 was performed by Long-yuan (2009). He analysed the influence of different support conditions at both the tension and compression ends of the web on the critical stress 
of distortional buckling of sigma purlins. Moreover he performed the comparison with finite strip analysis. The general explicit analytical formulae to provide distortional critical stress for coldformed steel C-section columns subjected to uniform compression was derived in Zhou et al. (2015) by employing the Lau and Hancock model and by introducing a new factor for considering the web rotational restraint reduced by web bending.

Tab. 1. The buckling modes of axially loaded thin-walled sigma profile

\begin{tabular}{|l|c|c|}
\hline \multicolumn{3}{|c|}{ Buckling modes } \\
\hline local buckling & \multicolumn{2}{c|}{ distortional buckling } \\
\hline & & \\
\hline
\end{tabular}

In this paper the local and distortional buckling analyses of cold-rolled sigma profiles were performed. In the first part of the study three numerical models were created using Finite Element Method. The buckling analyses were conducted to prove that the sigma cross-section can be successfully replaced by channel cross-section with additional elastic supports placed in folds of the web. Then, based on the assumption that the folds of the web (additional elastic supports) reduce the slenderness of the web the critical distortional stress was calculated basing on Eurocode recommendations and Hancock and Schafer formulas. In the second part, the FEM numerical model corresponding to Eurocode recommendation was created in order to verify the assumptions introduced in the analytical analysis and to investigate the interactive buckling, which is not taken into account in analytical formulas.

\section{BUCKLING FEM ANALYSIS}

\subsection{Linear eigenvalue problem}

In the numerical computations the values of critical buckling load for axially loaded channel and sigma bars were computed by solving the linear eigenvalue problem:

$\left(\mathbf{K}^{O}+\lambda \mathbf{K}^{G}\right) \mathbf{U}=0$,

where: $\mathbf{K}^{O}$ - is the small-displacement stiffness matrix, $\mathbf{K}^{G}-$ is the initial stress matrix, $\lambda$ - is the load multiplier and $\mathbf{U}$ - is eigenvector represents the buckling mode shapes. In Eq. (1) the proportional loading and linearization of the pre-buckling state was assumed. The critical buckling loads are given by the following formula:

$P^{c r}=\lambda^{c r} P$,

where: $P$ - is the reference load (the base state).

\subsection{Numerical model 1}

The real and simplified numerical model was created using Abaqus CEA software (Abaqus 6.13 Documentation). In the simplified model the sigma cross-section was replaced by channel cross-section with supports as shown in Fig. 1. The main aim of this part of the study was to verify the influence of supports on the value of critical stress.

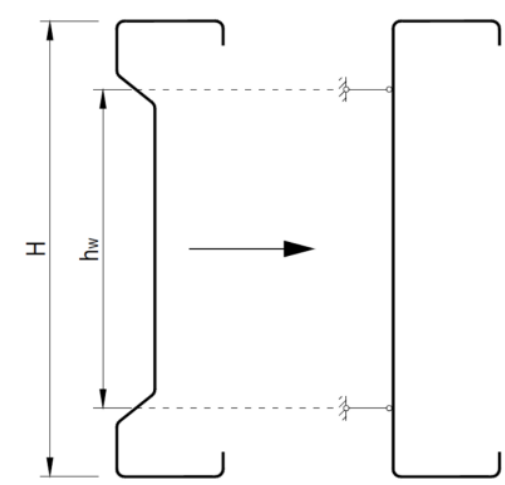

Fig. 1. Geometry of numerical model 1: a) real cross-section, b) simplified model: channel with additional supports

The element was meshed by four nodes shell finite elements S4R with dimension $4 \times 4 \mathrm{~mm}$. $\mathrm{R}$ means that the reduced integration was used. The axially compressive forces were applied to the special defined reference points. The reference points were created in the gravity centre of the cross section on he both side of the beam as shown in Fig. 2. The reference points were connected with the cross-section by coupling constraints. The boundary conditions were created to imitate a static shame of simply supported beam and then were also applied to the reference points. The computation were performed in Abaqus CEA program using Buckling Type of analysis in order to calculate the load proportionality factor.

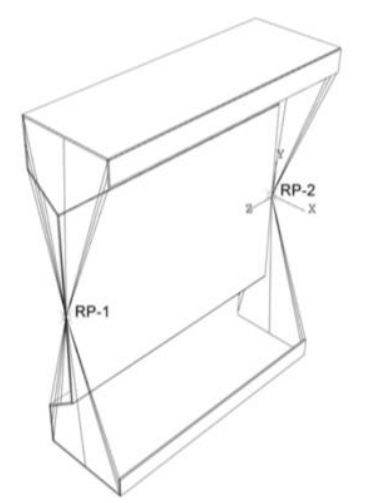

Fig. 2. The reference points in one of the created models 
The analysis was performed for several cold-formed symmetrical channel and sigma profiles with dimensions shown in Fig. 3 (flange width $b=70 \mathrm{~mm}$, wall thickness $t=1.5 \mathrm{~mm}$ and the lip width $c=16 \mathrm{~mm}$ ). The six different values of height of the cross section $(H=140,200,230,260,300$ and $350 \mathrm{~mm})$ and different slenderness ratio of the bar $(\mathrm{L} / \mathrm{i}$ min $=10,25,50,75,100,125,150$, 200 and 250) were analysed.

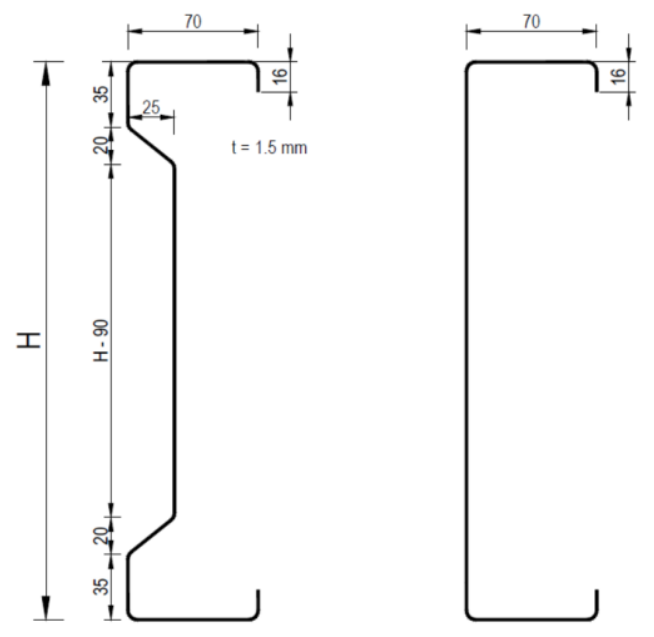

Fig. 3. Dimensions of the analysed models

\subsection{Results - numerical model 1}

The values of critical stress were calculated for several values of slenderness ratio (the beam length vs radius of gyration). In majority of the analysed cases the local and global interactive buckling phenomena was observed.

Exemplary results obtained in buckling analysis for the crosssection of the height of $230 \mathrm{~mm}$ and different slenderness ratio were presented in the Fig. 4.

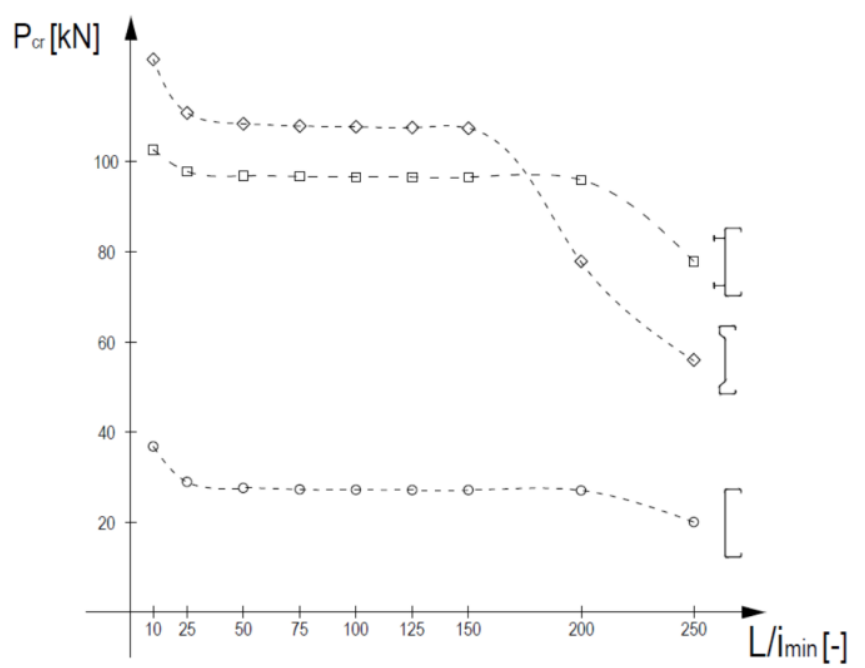

Fig. 4. The values of the critical load $\left(P_{c r}\right)$ as a function of concentric axially loaded thin-walled bar slenderness radio $(\mathrm{L} / \mathrm{min})$

It was found that for the large values of the slenderness ratio $(200 \div 250)$ the dominant buckling mode was the global one. This buckling mode was successfully described by Vlasov theory. As it was mentioned before, for the lower slenderness ratio the local and global interactive buckling occur. The same phenomena was observed as well in the case of the channel, sigma and simplified model.

It is worth to mention that obtained results for the sigma and simplified model (Fig. 1) remained in the compliance for the slender ratio $(10$ - 150). The slightly different behaviour was observed for the higher slenderness ratio when the global buckling occurred.

For slenderness ratio equal less than or equal to 100 the pure local buckling mode was extracted. The obtained results for this case were presented in Tab. 2. The local forms of buckling for the cross-section for the height of $230 \mathrm{~mm}$ were presented in the Fig. 5.

Tab. 2. The values of critical stress for different height of the cross-section

\begin{tabular}{|c|c|c|c|}
\hline \multicolumn{3}{|c|}{$\begin{array}{c}\text { The critical stress } \\
\sigma_{\text {cr }}[\mathrm{MPa}]\end{array}$} \\
\hline $\begin{array}{c}\mathrm{H} \\
{[\mathrm{mm}]}\end{array}$ & $\Gamma$ & 5 \\
\hline \multicolumn{4}{|c|}{ L/imin $\leq 100-$ local buckling } \\
\hline 140 & 134.30 & 445.49 & 455.60 \\
\hline 200 & 79.90 & 293.79 & 322.91 \\
\hline 230 & 45.66 & 162.60 & 170.62 \\
\hline 260 & 52.19 & 120.62 & 145.11 \\
\hline 300 & 44.06 & 84.98 & 97.03 \\
\hline 350 & 40.60 & 67.87 & 74.14 \\
\hline
\end{tabular}

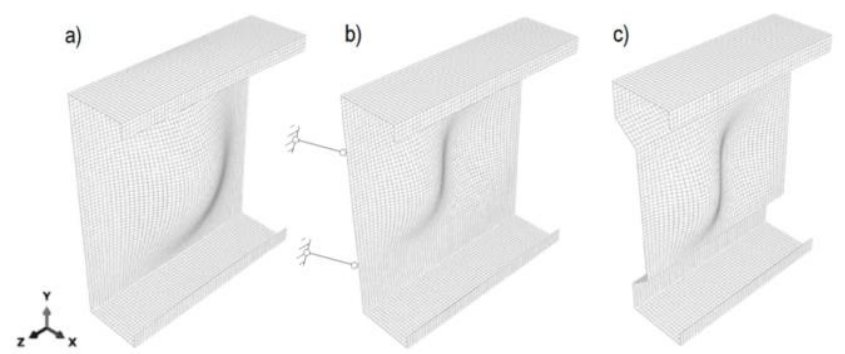

Fig. 5. The local forms of buckling for: channel (a), channel with additional supports (b) and sigma (c) cross-section

One can noticed that applying the simplified model (Fig. 5 b) provides the similar results comparing to the real sigma crosssection both in the shape of the buckling mode and the value of critical buckling stresses (Tab. 2).

\section{DISTORTIONAL BUCKLING}

\subsection{Theoretical background}

The critical distortional buckling stress for edge or intermediate stiffener according to (Eurocode 3, 2006) is evaluated from:

$\sigma_{c r, s}=\frac{2 \sqrt{K E I_{s}}}{A_{s}}$

where: $K-$ is the spring stiffness per unit length according to 
the formula (4), $A_{s}$ - is the area of the effective cross-section, $I_{S}$ - is the moment of inertia of the effective cross-section.

$K=\frac{E t^{3}}{4\left(1-v^{2}\right)} \cdot \frac{1}{b_{1}^{2} h_{w}+b_{1}^{3}+0,5 b_{1} b_{2} h_{w} k_{f}}$,

where: $t$ - is flange thickness, $h_{w}$ - is the web depth, $b_{1}, b_{2}-$ is the distance between the web-to-flange junction and the gravity centre of the effective area of the edge stiffener of flange respectively 1 or $2, k_{f}$ - is the ratio which is equal to 1 for a symmetric section in compression.

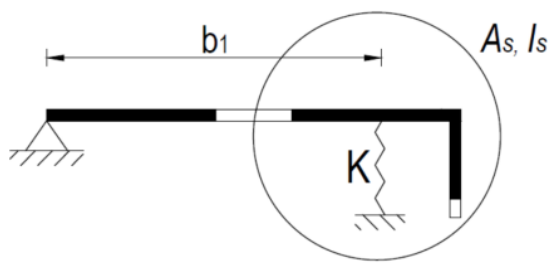

Fig. 6. The model used to analyse distortional buckling according to EN-1993-1-3 (Eurocode 3, 2006)

Alternatively, the critical distortional buckling stress can be calculated from the equations formulated by Lau and Hancock (5) or from formula proposed by Schafer (8).

$\sigma_{c r}=\frac{E}{2 A_{f}}\left[\left(\alpha_{1}+\alpha_{2}\right)-\sqrt{\left(\alpha_{1}+\alpha_{2}\right)^{2}-4 \alpha_{3}}\right]$,

where: $\mathrm{A}_{\mathrm{f}}$ - is the cross-sectional area of the flange and lip, $\alpha_{1}, \alpha_{2}, \alpha_{3}$ - are coefficients dependent on the geometrical characteristics and the value of elastic rotation spring stiffness $\mathrm{k}_{\phi}$ (Fig. 7).

The main idea of the Lau and Hancock method is to determine the flexural - torsional buckling critical stress of the model shown in the Fig. 7, where $h_{y}$ and $h_{z}$ are the coordinates of the centroid of flange and lip and $\mathrm{k}_{2}$ is the translational spring stiffness.

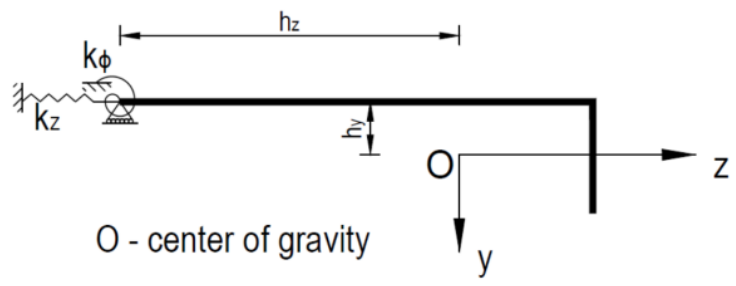

Fig. 7. The Lau and Hancock model

This method can be used only in the case when the value of rotation spring stiffness is greater than 0 . The modification of Lau and Hancock method for the case when the value of rotation spring stiffness is less than 0 was proposed by Davies and Jiang (1996). Two additional variables were introduced: $\sigma_{c r}^{\prime}-$ stress determined by the formula (5) assuming $\mathrm{k}_{\phi}=0$ and $\sigma_{\mathrm{w}}-$ the web critical buckling stress (6).

$\sigma_{w}=\frac{\pi^{2} D}{t h_{w}^{4}}\left(\frac{h_{w}^{2}+\lambda^{2}}{\lambda}\right)^{2}$

where: $D$ - is plate stiffness, $\lambda$ - is the half - wavelength.

Finally the distortional critical buckling stress (when $\mathrm{k}_{\phi}<0$ ) can be determined using following formula: $\sigma_{c r}=\frac{2 \sigma_{c r}{ }^{A} f+\sigma_{w} t h_{w}}{A}$,

where: $A$ - is the total area of the cross-section.

However, the critical stress proposed by Schafer is given as a function of rotational stiffness of the support at the point of the flange-web junction.

$\sigma_{c r}=\frac{k_{\varphi f e}+k_{\varphi w e}}{k_{\varphi f g}+k_{\varphi w g}}$,

where: $k_{\varphi f e}, k_{\varphi w e}$-are elastic rotational spring stiffness of the flange and web and $k_{\varphi f g}, k_{\varphi w g}$ - are geometric rotational spring stiffness of the flange and web.

\subsection{Numerical model 2}

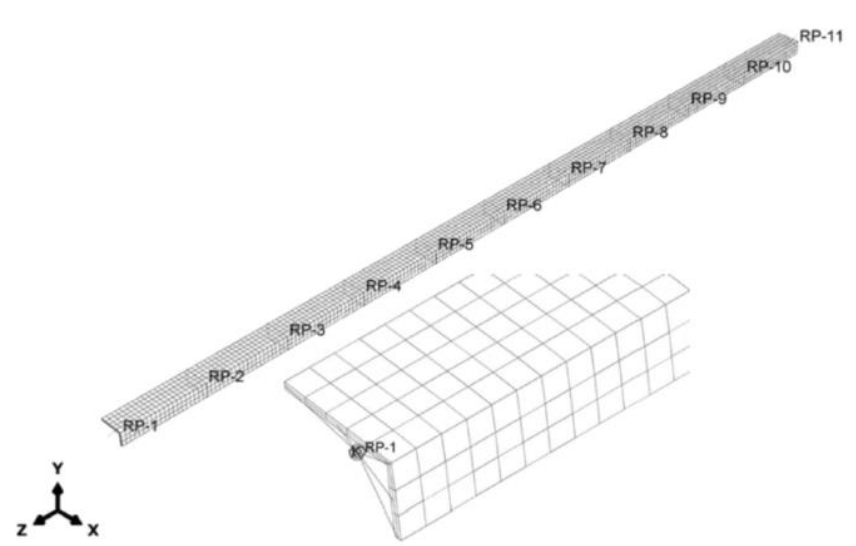

Fig. 8. The numerical model 2

To verify the analytical models presented in the paragraph 3.1 the numerical model 2 using finite element method and shell elements S4R was created. In numerical model 2 (Fig. 8) the boundary conditions and geometry were applied according to the Eurocode 3 recommendations (Fig. 6). The elastic spring supports were modelled with the stiffness equal to the value determined from the formula 4.

The numerical examples were carried out for the simplified model which corresponded to the sigma cross-section with the high $\mathrm{H}=140,200,230,260,300$ and $350 \mathrm{~mm}$. Based on the conclusions drawn from analysis conducted in paragraph 2.3, during the calculations of critical distortional stress using Eurocode, Hancock and Schafer formulas the reduce value of the web height (hw) was applied (distance between two additional elastic supports Fig. 1). The obtained results was compared with the FEM numerical model corresponding to Eurocode equivalent cross-section. The results of the calculations were presented in Tab. 3.

Tab. 3. The critical distortional buckling stress

\begin{tabular}{|c|c|c|c|c|c|}
\hline $\begin{array}{c}\mathbf{H} \\
{[\mathrm{mm}]}\end{array}$ & $\begin{array}{c}\mathbf{h}_{\mathbf{w}} \\
{[\mathrm{mm}]}\end{array}$ & $\begin{array}{c}\text { Shafer } \\
{[\mathrm{MPa}]}\end{array}$ & $\begin{array}{c}\text { Lau-Hancock } \\
{[\mathrm{MPa}]}\end{array}$ & $\begin{array}{c}\text { EN 1993-1-3 } \\
{[\mathrm{MPa}]}\end{array}$ & $\begin{array}{c}\text { FEM } \\
{[\mathrm{MPa}]}\end{array}$ \\
\hline 140 & 50 & 423.01 & 341.56 & 323.61 & 308.49 \\
\hline 200 & 110 & 266.90 & 245.75 & 250.69 & 262.83 \\
\hline 230 & 140 & 216.18 & 211.25 & 228.85 & 242.66 \\
\hline 260 & 170 & 172.60 & 177.27 & 211.89 & 220.76 \\
\hline 300 & 210 & 124.87 & 129.06 & 194.19 & 213.57 \\
\hline 350 & 260 & 81.65 & 102.43 & 117.28 & 129.21 \\
\hline
\end{tabular}




\section{CONCLUDING REMARKS}

In this paper the local and distortional buckling analyses of axially loaded cold-rolled channel and sigma profiles were performed. The special attention was focused on creating the simplified models of sigma cross-sections which allowed for applying the analytical formulas for calculation of distortional buckling derived for the channel cross-section. For this purpose the finite element models were created in order to verify simplified formulas implemented in Eurocode and proposed by Hancock and Schafer. The performed buckling analyses proved that the sigma crosssection can be successfully replaced by channel cross-section with additional elastic supports placed in folds of the web. It was demonstrated that the folds in the web of the sigma cross-section (additional elastic supports) reduce the web slenderness. So, the critical distortional stress can be calculated based on analytical formulas derived for the channel cross-section taking into account the web height between the folds $\left(h_{w}\right)$.

\section{REFERENCES}

1. Abaqus Documentation - version 6.13 , http://www.abaqus.com

2. Davies J.M., Jiang C. (1996), Design of thin walled columns for distortional buckling, Proceedings of the Second International Conference on Coupled Instability in Metal Structures CIMS'96, Liege, Belgium.

3. EN 1993-1-3, Eurocode 3 (2006), Design of steel structures Part 1-3: General rules - Supplementary rules for cold-formed members and sheeting.

4. He Z., Zhou X., Liu Z., Chen M. (2014), Post-buckling behaviour and DSM design of web-stiffened lipped channel columns with distortional and local mode interaction, Thin-Walled Structures, 84, 189-203.
5. Lau, S.C.W., Hancock, G.J. (1990), Inelastic buckling of channel columns in the distortional mode, Thin - Walled Structures, 10, 59-84.

6. Long-yuan Li (2009), Analyses of distortional buckling of coldformed sigma purlins using EN 1993-1-3, Journal of Constructional Steel Research, 65, 2099-2102.

7. Long-yuan Li, Jian-kang Ch. (2008), An analytical model for analysing distortional buckling of cold-formed steel sections, Thin - Walled Structures, 46, 1430-1436.

8. Pala M. (2006) A new formulation for distortional buckling stress in cold-formed steel members, Journal of Constructional Steel Research, 62, 716-722.

9. Pala M., Caglarb N. (2007), A parametric study for distortional buckling stress on cold-formed steel using a neural network, Journal of Constructional Steel Research, 63, 686-691.

10. Schafer B.W. (2000), Distortional buckling of cold-formed steel columns, Final Report of AISI.

11. Schafer B.W. (2008), Review: The Direct Strength Method of coldformed steel member design, Journal of Constructional Steel Research, 64 766-778.

12. Szymczak C., Werochowski W. (2005), Distortional instability of axially loaded cold-formed elements with stiffened flanges (in Polish), Inżynieria i Budownictwo, R. 61, 2, 85-88.

13. Wang L., Young B. (2014), Design of cold-formed steel channels with stiffened webs subjected to bending, Thin-Walled Structures, 85, 81-92.

14. Yua C., Schafer B.W. (2007),Simulation of cold-formed steel beams in local and distortional buckling with applications to the direct strength method, Journal of Constructional Steel Research, 63, $581-590$

15. Zhou X., Liu Z., , He Z. (2015), General distortional buckling formulae for both fixed-ended and pinned-ended C-section columns, Thin-Walled Structures, 94, 603-611.

Financial support by the grant $01 / 11 / \mathrm{DSPB} / 0605 / 2016$ DSPB is kindly acknowledged. 